\title{
Pinar Kayaalp, The Empress Nurbanu and Ottoman Politics in the Sixteenth Century: Building the Atik Valide, New York: Roudledge, 2018, xii+172 s. ISBN: 978-1138099791
}

Ayşegül Ünal' ()

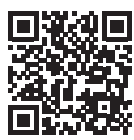

'Sorumlu yazar/Corresponding author: Ayşegül Ünal (Doktora Öğrencisi), İstanbul Üniversitesi, Edebiyat Fakültesi, Tarih Bölümü, İstanbul, Türkiye E-posta: aysegulunal.trh@gmail.com ORCID: XXXX

Başvuru/Submitted: 15.07.2020

Kabul/Accepted: 08.09.2020

Atif/Citation: Unal, Aysegul, "Pinar Kayaalp, The Empress Nurbanu and Ottoman Politics in the Sixteenth Century; Building the Atik Valide, New York: Roudledge, 2018" (Kitabiyat). GüneyDoğu Avrupa Araştırmaları Dergisi, 34 (2020), s. $133-136$.

https://doi.org/10.26650/gaad.20213407

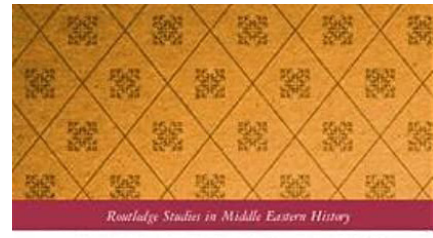

THE EMPRESS NURBANU AND OTTOMAN POLITICS IN THE 16TH CENTURY BUILDING THE ATIK VALIDE

Pinar Kayaalp

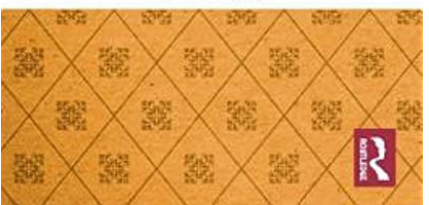


Osmanlı geleneğinde imparatorluğa ait külliye inşası, hanedanın yalnızca seçkin üyelerine tanınmış bir ayrıcalık olarak ortaya çıkmıştır. 16. yüzyılın ortalarından itibaren Osmanlı Hanedan politikalarına kadınların da dahil olmasıyla birlikte büyük inşa faaliyetlerinde de bir değişim meydana gelmiş, banilik padişahın gözde cariyesinden valide sultana geçmiştir. II. Selim'in hasekisi ve III. Murad'ın annesi Nurbanu Sultan (1525-1583) Osmanlı hanedanının en önemli kadın sultanlarından olmasına rağmen hakkında yapılmış çalışmalar kısıtıdır. Manisa sancağında bulunan Şehzade Selim tarafından gözde haseki seçildiği 1542 yılından itibaren Nurbanu Sultan'ın siyasi ve idari kariyeri de başlamış bulunmaktadır.

Pınar Kayaalp kitabının amacını tanımlarken, Atik Valide Külliyesi ve banisine dair ilk tam monografiyi hazırlamayı hedeflediğini vurgulamaktadır. Kitabın bölümleri, bu amaçla 16. yüzyılda Osmanlı sarayında hamiliğin kadınlar tarafından mimaride nasıl kullanıldığını okuyucuların göreceği şekilde tasarlanmıştır. Çalışma, bu dönemdeki kadın hamiler ve mimari eserler arasındaki ilişkiyi ilerleyen bölümlerde karşılaştırmalı örnekleriyle açıklamaktadır. "The shift in the Ottoman patronage system between the sixteenth and seventeenth centuries" (s. 1-11) isimli ilk bölümde öncelikle genel bir vakıf tanımı yapılmakta ve vakıf kurumu hakkında bilgi verilmektedir. Ardından Osmanlı Devleti'nde mimari, sanat ve edebiyat alanlarında altı yüzyıl boyunca var olan himaye sistemi incelenmekte ve bu sistemin siyasi, sosyal ve ekonomik değişimler ile paralel ilerlediği belirtilmektedir.

"The emergence and rise of Nurbanu in Ottoman dynastic politics" (s. 12-47) başlıklı ikinci bölüm II. Selim'in Kanuni Sultan Süleyman'ın ölümü sonrası cülusuyla birlikte gelişen olayların anlatımı ile başlamaktadır. Kayaalp bu bölümde, öncelikle II. Selim'e yapılan eleştirilerden bahsetmektedir. Bu eleştiriler padişahın saraydan ayrılmayarak seferlere katılmamasına, kişisel hayatına ve yakın arkadaşları ile gözde devlet adamlarına karşı takındığı fazla hoşgörülü tavrına yöneliktir. Ancak Kayaalp'e göre bu eleştiriler tutarlı ve geniş kapsamlı değildir. Eleştirenlerin hepsi aynı kişiye aynı suçlamalarda bulunmamaktadır. Ayrıca imparatorluğun artık daha bürokratik bir yapıya kavuştuğu ve yeni padişahların rollerinin daha sembolik olduğu göz ardı edilmektedir. Kayaalp Osmanlı müverrihlerinin ve yabancı gözlemcilerin kendi çıkarları doğrultusunda yorum yapabileceklerini de göz önünde bulundurmamız gerektiğini hatırlatmaktadır. Bu iddiasını Gelibolulu Mustafa Âlî, Venedik balyosu Marcantonio Barbaro ve Costantino Garzoni örneklerini vererek güçlendirmektedir.

II. Selim'in toplum nezdinde "dinsiz, gösterişli, obur ve şarap sever" şeklinde olumsuz bir imajı olduğunu vurgulayan Kayaalp, sultanın diğer bir olumsuz imajının da askeri meselelere ilgisizliği olduğunu belirtmektedir. Bütün bunların yanı sıra Osmanlı kroniklerinin ve özellikle yabancı kaynakların aktardıklarından yola çıkarak bu dönemde hanedan mensubu kadınların siyasi meselelerdeki etkisi hakkında önemli bilgiler vermektedir. Özellikle II. Selim'in hasekisi Nurbanu'nun devletlerarası ve hanedan içi siyasete katıımı konusunda Venedik balyoslarının ve elçilerinin aktardığı önemli bilgiler mevcuttur. Venedik Arşivi'nde rastlanan bu bilgilerden ilki 1558 yılının başlarına tarihlenmektedir. Şehzade Selim, Hasan Çavuş isimli birini gözdesi 
Nurbanu'nun soyu hakkında bilgi toplaması için Venedik'e göndermiştir. Bunun üzerine senato şehzadeye bir mektup yollamış ve böylece Nurbanu'nun geçmişi öğrenilmiştir. Kitabın bu bölümünde Nurbanu'nun biyografisini ayrıntılarıyla yazan Kayaalp, Hasan Çavuş'un da aktardığı bilgilerden yola çıkarak 1525 yılında Paros Adası'nda doğan Nurbanu'nun asıl isminin Cecilia, babasının Paros dükü Nicolò Venier ve annesinin Violante Baffo olduğunu belirtmektedir. Mektupta ayrıca Zuan Francesco Venier isimli Korfu kalesi kumandanının Cecilia'nın babasının kardeşi yani amcası olduğu da yazılmıştır. Bu bilgiler Nurbanu Sultan'ın köklü bir ailenin kızı olduğunu göstermesi açısından kayda değerdir. Daha sonra Hasan Çavuş, 1559 yilında Venedik'e ikinci kez gitmiş ve böylece Nurbanu tarihi kaynaklarda bir kez daha ortaya çıkmıştır. 1559'da Hasan Çavuş'un ikinci Venedik ziyareti ile 1574'te III. Murad'ın tahta çıkması arasında geçen süre içerisinde Venedik kaynakları Nurbanu'dan üç kez bahsetmektedir. Bu bölüme ana hatlarıyla baktığımızda Nurbanu'nun hem hanedan içerisinde hem de dışında kendisine siyasi ve diplomatik bir çevre edindiğini rahatıkla görmekteyiz. Giriş bölümünde de belirtildiği gibi çalışmanın bu bölümünde Kayaalp, Nurbanu'nun hanedan içerisinde üstün bir konuma erişmek için yaşamış olduğu zorlukları ve kendisinin baskın gelmesi sonucu ortaya çıkan birtakım sürtüşmeleri ele almaktadır.

“The written records of the Atik Valide" (s. 48-70) bölümünde ise Nurbanu Sultan'ın vakfiyesini inceleyen Kayaalp, önce vakfiyenin metinsel incelemesini daha sonra da Atik Valide Külliyesi'nin kitabe ve diğer yazıtsal değerlendirmesini yapmaktadır. Vakfiyenin dua kısmını detaylı bir şekilde ele alan Kayaalp, bu kısımda caminin içerisinde; mihrap ve son cemaat yerinde yer alan sureleri ve ne anlama geldiklerini de incelemiştir. Camide yer alan ayetlerden yola çıkan yazar, Nurbanu'nun kişisel ve geleneksel bir yapı inşa ettirme niyetinde olduğunu söylemektedir.

Mihrimah Sultan Camii'nin kitabesi ile Nurbanu Sultan'ın kitabesini karşılaştıran yazar, Nurbanu'nun kitabesinin tahtadan yapılmış olmasına rağmen bir yönüyle oldukça üstün olduğunu belirtmiştir, bu üstünlüğü ise Mihrimah Sultan'ın kitabesinde kendi adının geçmediğini ancak Nurbanu Sultan'ın meşruiyetini kocasından yahut oğlundan almadığını belirterek desteklemektedir. Ayrıca bu kısımda III. Murad'ın nasıl tasvir edildiği meselesini incelemekte ve buradan yola çıkarak tüm vakfiyelerin aynı zamanda oldukça kişisel olduğu ve bazı açılardan mesaj ilettiği yargısına varmaktadır. Caminin içerisinde yer alan bu yazıtlardan da yola çıkan yazar, Nurbanu'nun bu görkemli hayır işini kocası ve eşinden bağımsız olarak meydana getirdiğinin altını çizmektedir.

Kayaalp'e göre Nurbanu'nun kendisinin, oğlunun ve imparatorluğun imajı vakfiye metninde ve külliyede yer alan metinlerde dikkatlice işlenmiştir. Bu bölümün en güçlü tezlerinden biri ise Nurbanu'nun vakfiyesinde kendisi örnek bir Müslüman olarak gösterilirken, oğlunun ise halifeliğin koruyucusu ve hanedanın devamlıı̆ııı sağlayan üstün ahlaklı ve adil bir hükümdar olarak lanse edilmesidir. Vakfiyenin hazırlandığı vakit Nurbanu'nun henüz hayatta olması yapılan bu çıkarımları daha önemli ve güçlü hale getirmektedir. Ayrıca Kayaalp, Valide 
Sultan'ın padişaha yöneltilen eleştirilerin farkında olduğu ve kendisinin yapması gerekenleri iyi bildiği sonucuna ulaşmaktadır.

Dördüncü bölüme geldiğimizde Nurbanu'nun inşa ettirdiği külliyenin fonksiyonel ve simgesel önemi ele alınmaktadır. "The functional and iconographic significance of Nurbanu's monument" (s. 71-112) başlıklı bu son bölümde ilk olarak külliyenin topografik açıdan değerlendirilmesiyle başlayan Kayaalp, II. Mehmed'den itibaren inşa ettirilen yapıların konumlarına bakarak görünürlüğün tek amaç olmadığını, II. Mehmed, II. Bayezid, I. Selim ve I. Süleyman'ın yaptırdığı camilere bakarak Rum diyarındaki Osmanlı üstünlüğünü göstermeyi amaçladıklarını belirtmektedir. II. Mehmed'in saltanatından sonra kentsel yapıya dair endişeler gücünü yitirmiş, II. Bayezid Külliyesi örneğinde olduğu gibi büyük yapıların inşasında geniş kamusal alanlara ihtiyaç duyulmuştur. Mimar Sinan ise var olan kentsel yapıya elinden geldiğince uymaya çalışmıştır.

16. yüzyılın ikinci yarısına geldiğimizde Nurbanu büyük projesini tamamlamış ve İstanbul çoktan Osmanlı tarzı ikonografiyi yansıtan bir şehir haline gelmişti. Külliyenin tamamlanmasıyla Üsküdar, sufilerin ve sünnilerin bir arada var olduğu bir merkez haline gelmiş, dini, sosyal ve ticari açıdan önemli değişimler yaşamıştır. Bu durum Üsküdar'ın askeri ve ticari bir merkez olmaktan çıkıp bireysel ve kamusal inşa hareketiyle bir şehir merkezine dönüşmesine neden olmuştur. Hanedan mensubu kadınların yaptırmış olduğu külliyeler ise çalışmanın bu kısmında Atik Valide külliyesi ile karşılaştırılmaktadır. Özellikle Sinan'ın bir diğer önemli projesi olan Mihrimah Sultan Külliyesi'nin Üsküdar'ın bu dönüşümünde Atik Valide ile birlikte önemli bir rol oynadığı düşünülmektedir.

Kayaalp kitabın başında vadettiği gibi Nurbanu Sultan hakkında yapılan ilk tam monografiyi hazırlamıştır. Valide Sultan'ın biyografisinin yanı sıra baniliği ve etrafında gelişen siyaseti birden fazla yönüyle ele almayı başarmıştır. Osmanlı hanedan mensubu kadınların inşa hareketlerinin ne denli önem arz ettiğini bu çalışma sonucunda bir kez daha görebilmekteyiz. 